Dear Author,

Please, note that changes made to the HTML content will be added to the article before publication, but are not reflected in this PDF.

Note also that this file should not be used for submitting corrections. 


\title{
Expression of biotic stress response genes to Phytophthora infestans inoculation in White Lady, a potato cultivar with race-specific resistance to late blight
}

\author{
Q3 Ramin Hajianfar ${ }^{\text {a, b, c }}$, Balázs Kolics ${ }^{\mathrm{a}}$, István Cernák ${ }^{\mathrm{b}}$, István Wolf ${ }^{\mathrm{b}}$, Zsolt Polgár ${ }^{\mathrm{b}}$, \\ János Taller ${ }^{\text {a, * }}$ \\ ${ }^{a}$ Department of Plant Science and Biotechnology, University of Pannonia, H-8360 Keszthely, Deák Ferenc u. 16., Hungary \\ ${ }^{\mathrm{b}}$ Potato Research Centre, University of Pannonia, H-8360 Keszthely, Deák Ferenc $u$. 16., Hungary \\ c Department of Vegetable Research, Seed and Plant Improvement Institute, Mahdasht Avenue, P.O. Box 31585-4119, Karaj, Iran
}

\section{A R T I C L E I N F O}

\section{Article history:}

Received 13 October 2014

Received in revised form

27 November 2015

Accepted 1 December 2015

Available online $\mathrm{xxx}$

\section{Keywords:}

Phytophthora infestans

Late blight

Solanum tuberosum

Potato

Biotic stress response genes

qPCR

Gene expression

Q1 Biotrophic phase

\begin{abstract}
A B S T R A C T
Expression changes of biotic stress response genes were analyzed during a $65 \mathrm{~h}$ period post inoculation with Phytophthora infestans in potato cultivar White Lady that possesses race-specific resistance to this pathogen. All analyzed respiratory burst oxidase homologs, the PR proteins, the serine-, cysteine- and aspartic protease inhibitors, as well as the Rpi-bt1 gene homolog were up-regulated in the biotrophic phase. The $R 1$ and $R 2$ gene homologs showed up-regulation only at $65 \mathrm{hpi}$, and interestingly, the $R 3 a$ gene showed only a very slight expressional increase. It is concluded, that beside the constitutively expressed $R$ genes a number of non-specific stress response genes contribute to the successful resistance response in race-specific defense.
\end{abstract}

() 2015 Published by Elsevier Ltd.

\section{Introduction}

Late blight, caused by Phytophthora infestans is one of the most serious potato diseases worldwide. It can cause total crop loss and severe economic hardship to potato growers [1]. Considering the known resistance sources in wild potato species, breeding for resistance represents an alternative to fungicide application. $P$. infestans resistance genes in potato are classified as race-specific and race-nonspecific resistance genes. Race-specific are the $R$ genes $(R 1-R 11)$ that originate from the wild Solanum species Solanum demissum. These have been introgressed into many potato cultivars [2]. Race-nonspecific resistance genes (Rpi genes) have been identified in different wild Solanum species (see recent reviews by Tiwari et al., 2013 and Rodewald and Trognitz, 2013) [3,4], and several of them have been isolated recently [5-11].

\footnotetext{
* Corresponding author.

E-mail address: taller@georgikon.hu (J. Taller).
}

Late blight is identified by rapidly expanding lesions with visible white growth at the leading edge on the abaxial leaf surface of sensible potato plants. The rapidly spreading pathogen can destroy the entire plant in a few days, after the first lesions were observed. Infected potato tuber tissues are brownish in color, and are often invaded by soft rot bacteria which rapidly invade adjoining healthy tissues [12].

In race-specific resistance, local lesions appear at the infection site but do not develop further due to the incompatible interaction of the $R$ gene and the corresponding avirulence (Avr) gene of the pathogen. Compared to this, race-nonspecific resistance is not correlated with hypersensitive response, and instead involves limiting pathogen spread in the host [10].

In resistant genotypes $P$. infestans infection triggers a systemic acquired resistance (SAR) response, where the expression of SAR genes correlates with local necrotic lesions [13]. In SAR signals are transported from the infection site to other parts of the plant. These signals stimulate the production of molecules designated as components of the defense response pathways including resistance 
proteins like pathogenesis related (PR) proteins, proteinase inhibitors (PI), reactive oxygen species (ROS), antimicrobial compounds and various other groups of molecules which are involved in the hypersensitive response (HR) [14-20].

According to previous inoculation tests, cultivar White Lady is known to possess the $R 1, R 2, R 3, R 4, R 6, R 7, R 10$ and $R 11$ race-specific resistance genes. With whole genomic transcriptome analysis of this cultivar previously we could identify the complete sequence of the $R 3 a$ gene that was isolated in 2005 by Huang et al. [21]. Besides the $R 3 a$ gene, homologs of the $R 1$ and $R 2$ genes, and interestingly, 82 Rpi gene homologs were also detected by that transcriptome analysis (unpublished results).

For more information about the potato cultivar White Lady visit the following website: http://www.europotato.org/display_ description.php?variety_name=WHITE\%20LADY.

In order to understand the molecular mechanism of systemic acquired resistance, besides the expression of resistance genes, it is essential to figure out the role of defense metabolites. Analysis of $P$. infestans induced gene expression changes would be important to determine those genes which are involved in resistance response, as well as to characterize their function in SAR. To this end, qPCR would be an effective approach, since it allows the measuring of the relative expression level of a particular transcript in a given sample type and determines its expression after being exposed to a specific alteration, such as infection by a pathogen [22].

Phytophthora species mostly start the infection in a biotrophic interaction with the host and switch later to a necrotrophic phase. This type of interaction between pathogen and host is known as hemibiotroph [23]. P. infestans requires living plant cells for survival in the biotrophic phase. During this phase nutrients are obtained from the living plant cells. This is achieved by forming a penetration peg, then haustoria by the branching hyphae and the subsequent secretion of enzymes that degrade components of the plant cell wall. Different signals of the pathogen are involved during infection, including physical pressure to penetration, apoplastic pathogen elicitors and cytoplasmic effectors. These stimuli trigger the downstream signaling pathways which regulate the expression of defense genes and induction of a hypersensitive response [24,25]. This phenomenon restricts the pathogen growth effectively and its containment before transition to the necrotrophic phase [25,26]. In resistant Solanum species the hypersensitive response against $P$. infestans occurs rapidly. Incompatible interaction after 36-48 h post inoculation (hpi), the mode of interaction between $P$. infestans and initially infected host cells becomes necrotrophic, and from 72 to $96 \mathrm{hpi}$, initially infected areas of the leaf are fully colonized and necrotic [27]. Nevertheless, how this switch from biotrophic to necrotrophic phase is inhibited in the resistant plants is still not understood.

In order to check the expression profile of biotic stress response genes in early stage of $P$. infestans inoculation, candidate genes were selected from a transcriptome dataset (hereafter Potato-TD) of the potato cultivar White Lady that is resistant to the P. infestans races presently widespread in Hungary. Since altogether several hundred gene candidates of different classes of biotic stress response genes were identified in the Potato-TD, $P$. infestans induced expression changes of the $R 3 a$ gene and 15 other, randomly selected transcripts representing PI, PR, ROS genes and resistance gene analogs were analyzed by qPCR in the present study.

\section{Materials and methods}

\subsection{Inoculation with P. infestans and sample collection}

Pathogen-free tubers of the cultivar White Lady were planted into pots and plants were grown in a vector-free greenhouse with a maximum $25^{\circ} \mathrm{C}$ day- and minimum $15^{\circ} \mathrm{C}$ night temperature. Four weeks after planting, the plants were sprayed with a mixed suspension of the H12/10 (avr1, 3, 4, 7, 10, 11) and 10/2010 (avr1, 2, 3, 4, $6,7,10,11$ ) isolates. Spraying of the inoculum suspension with $1.5 \times 10^{4}$ spore/ml concentration was done on the abaxial surface of leaflets on whole plants. For maintaining the required humidity for infection, plants were covered with a net cloth and were sprayed with water twice daily.

For mRNA isolation non-inoculated leaflets of inoculated leaves were collected at 1, 4, 17, 24, 35, 48 and 65 h post inoculation (hpi) and were immediately frozen in liquid nitrogen. At the same time points samples from mock inoculated plants were collected as control. Mock inoculation was done by spraying pathogen-free water on the plants.

\subsection{Selection of biotic stress response genes for expressional analysis}

The transcriptome dataset of White Lady was used to select biotic stress response genes for the analysis of possible expression changes of these genes in response to $P$. infestans inoculation. This transcriptome dataset was generated from RNA obtained from PVX, PVY and $P$. infestans inoculated plants of the potato cultivar White Lady. Inoculation was done with each pathogen on separate plants and samples were collected at different time points after inoculation. For control at the same time points samples from mock inoculated plants were collected too. Mock inoculation was identical with the inoculation method except that the pathogen was excluded from that. Transcriptome analysis (RNA-sequencing) was done on two RNA bulks, i.e. on the control and on the treated bulk. This later contains the inoculated samples. Each of these bulks represented in equal volumes each infection and each time point of sample collection. While details of the transcriptome analysis will be published elsewhere, here we just refer to the Potato-TD, as it was utilized for the selection of biotic stress response genes.

From among the several hundred transcripts which showed high sequence similarity with biotic stress response genes 16 genes were chosen in a way that they should represent defense related gene families. The selected gene families and genes that were analyzed in the present study are indicated in Table 1. Besides sequence similarity of transcripts and biotic stress response genes, the criterion of selection was that the transcript should be upregulated after inoculation. A gene was considered as upregulated when the RPKM (reads per kilobase per million mapped reads) [28] value of it was above 2.00 in the treated sample compared to the control. However, for the A, B and C homologs of the respiratory burst oxidase family $(R b o h)$ and for the $P R 10$ protein no up-regulation was observed, in the present study to compare their qPCR results with those of the transcriptome analysis, we included also these genes in the experiments.

\subsection{Purification of mRNA, cDNA synthesis and primer design}

Isolation of RNA was done with RNAzol (MRC, USA) according to the manufacturer's recommendations. DNA was removed with the DNase I kit (New England Biolabs Inc., UK) and the concentration of RNA was measured by a Nanodrop 2000 (Thermo Scientific, USA) spectrophotometer.

In order to quantify the gene expressional changes induced by $P$. infestans, a two-step reaction was used including the reverse transcription and the PCR procedure. Two-step quantitative realtime reverse transcriptase PCR (qRT-PCR) started with the reverse transcription of a poly(A)+ RNA into cDNA by using a reverse transcriptase enzyme. The reaction (first strand synthesis) was carried out with High-Capacity cDNA Reverse Transcription Kit 
Table 1

Characteristics of the genes in the Potato-TD that were selected for qPCR analysis.

\begin{tabular}{|c|c|c|c|c|c|c|}
\hline & Gene family & Gene function & SGN ID ${ }^{\mathrm{a}}$ & RPKM- control ${ }^{\mathrm{b}}$ & RPKM- treated ${ }^{\mathrm{b}}$ & Fold change $^{c}$ \\
\hline 1 & Protease inhibitors & Aspartic protease inhibitor (AspI) & PGSC0003DMG400009513 & $1.48(6)$ & $10.42(47)$ & 7.05 \\
\hline 2 & & Cysteine protease inhibitor (CyspI) & PGSC0003DMG400010134 & $0.66(2)$ & $9.46(32)$ & 14.40 \\
\hline 3 & & Kunitz-type protease inhibitor (KtpI) & PGSC0003DMG400015267 & $1.38(6)$ & $9.91(48)$ & 7.20 \\
\hline 4 & & Serine protease inhibitor (SerpI) & PGSC0003DMG400026953 & $3.12(88)$ & $6.99(219)$ & 2.24 \\
\hline 5 & Respiratory burst oxidase homologs & RbohC & PGSC0003DMG400014168 & $5.82(178)$ & $11.10(377)$ & 1.91 \\
\hline 6 & & RbohA & PGSC0003DMG400012316 & $2.54(22)$ & $3.43(33)$ & 1.35 \\
\hline 7 & & RbohB & PGSC0003DMG400024754 & $1.66(35)$ & $3.12(73)$ & 1.88 \\
\hline 8 & Antioxidant & Glutathione peroxidase (Glutp) & PGSC0003DMG402004978 & $2.99(64)$ & $18.01(428)$ & 6.02 \\
\hline 9 & $P R$ proteins & PR1 & PGSC0003DMG400037874 & $0(0)$ & $2.43(5)$ & Activated $^{\mathrm{d}}$ \\
\hline 10 & & PR10 & PGSC0003DMG402001494 & $2.93(16)$ & $2.96(18)$ & 1.01 \\
\hline 11 & Immune receptor & PPR1 & PGSC0003DMG400020554 & $3.26(83)$ & $18.52(524)$ & 5.68 \\
\hline 12 & $R$ gene \& $S$. demissum $R$ gene homologs & $R 1$ homolog & PGSC0003DMG400025545 & $1.54(33)$ & $2.23(53)$ & 1.44 \\
\hline 13 & & $R 2$ homolog & PGSC0003DMG401011522 & $2.42(33)$ & $8.30(126)$ & 3.44 \\
\hline 14 & & $R 3 a$ gene & PGSC0003DMG402030235 & $2.14(48)$ & $5.10(127)$ & 2.38 \\
\hline 15 & S. bulbocastanum Rpi-homologs & Rpi-bt1 homolog & PGSC0003DMG401007609 & $1.22(13)$ & $6.69(79)$ & 5.47 \\
\hline 16 & & Rpi-blb2 homolog & PGSC0003DMG400023253 & $2.97(30)$ & $8.02(90)$ & 2.70 \\
\hline
\end{tabular}

a Potato gene identification numbers according to the SOL Genomics Network (SGN).

b In parenthesis are the number of transcripts of the control, as well as of the treated sample.

c Fold change calculated from the RPKM values of the transcriptome dataset.

d That gene was not expressed in the control, but was activated by one or more of the infections.

with RNAse inhibitor, according to the manufacturer's recommendations (Life Technologies, USA). At $20 \mu \mathrm{l}$ final volume the concentration of mRNA was $1 \mathrm{ng} / \mu \mathrm{l}$ in the reaction solution. To give an equal representation of all targets in real-time PCR applications and to avoid the $3^{\prime}$ bias of oligo (dT) primers, random primers were utilized to synthesize the first-strand cDNA from mRNA with Multiscribe Reverse transcriptase (Life Technologies, USA). First strand synthesis was done in a thermal cycler using the following program: $25^{\circ} \mathrm{C}$ for $10 \mathrm{~min}, 37^{\circ} \mathrm{C}$ for $120 \mathrm{~min}$ in cycling stage and $85^{\circ} \mathrm{C}$ for $5 \mathrm{~min}$.

Specific PCR-primer pairs for the selected genes were designed with the Primer Express Software 3.0 (Life Technologies, USA) using the transcript sequences of the genes from the Potato-TD. In primer design the following criteria were used: length of amplicon: 50-150 bp; GC content of the primers: $30-85 \%$; melting temperature: $58-60{ }^{\circ} \mathrm{C}$; primer length: $9-40 \mathrm{bp}$; exclusion of 3 '-end matching of the forward and reverse primers.

\subsection{Quantitative RT-PCR analysis}

Quantitative analysis of the genes was performed with a StepOne Real-Time PCR Systems (Life Technologies, USA). Gene expression was analyzed on the basis of monitoring of thermal cycling with the fluorescent SYBR green binding dye [29]. Endogenous control was the housekeeping gene $\beta$-tubulin (Supplementary file 1) and the reference sample was mock inoculated sample (control). Quantification of the housekeeping gene and of the gene of interest was done with three biological replications for each sample. The qPCR reaction mix contained: $0.5 \mu \mathrm{M}$ of each primer, $2.1 \mathrm{ng}$ cDNA, $10 \mu \mathrm{l}$ of power SYBR green master mix and $7.45 \mu \mathrm{l}$ of molecular biology water (AccuGENE, Belgium). The reaction mixture was loaded on a MicroAmp Fast Optical 48-Well reaction plate (Life Technologies, USA) and sealed with an adhesive film. For obtaining optimal results, a standard ramp speed (2-h time) was selected for running the system. The qPCR profile was as follows: $95{ }^{\circ} \mathrm{C}$ for $10 \mathrm{~min}$ in holding stage, 40 cycles of $95{ }^{\circ} \mathrm{C}$ for $30 \mathrm{~s}$, annealing at the temperature for each primer pairs for $60 \mathrm{~s}, 95^{\circ} \mathrm{C}$ for $15 \mathrm{~s}$ in cycling stage and $95^{\circ} \mathrm{C}$ for $15 \mathrm{~s}, 60^{\circ} \mathrm{C}$ for $1 \mathrm{~min}$ and $+3{ }^{\circ} \mathrm{C}$ in step and hold to $95^{\circ} \mathrm{C}$ for $15 \mathrm{~s}$ during melting curve stage.

The comparative $\mathrm{Ct}$ method $(\Delta \mathrm{Ct})$ was used to assess the changes in fluorescence recorded during PCR reaction between treated samples and control. Among different endogenous controls the housekeeping gene $\beta$-tubulin with GI no. 609267 in NCBI had minimal changes between the treated and control samples; hence, it was used to normalize target genes in the $\mathrm{Ct}$ method. The characteristics of designed primers' sequences of this gene are described in Supplementary file 1 . The output data were analyzed by the StepOne software v2.3. The software determined the relative quantity of the target genes by comparing normalized target quantity in each sample to normalized target quantity in the reference sample.

The data of relative quantity for each gene in every time point were collected and statistically analyzed with nested design and the comparison of means was done by using of least significant difference (LSD) at probability level $<0.01 \%$.

\subsection{Gel electrophoresis, cloning and sequencing of qPCR amplified fragments}

In order to check whether the amplified fragments are at the expected size, qPCR products were separated on a $2 \%$ agarose gel with $200 \mathrm{~mA}$ direct current, then stained with ethidium bromide and documented with a GeneGenius (Syngene, UK) gel documentation system. Cloning was done using the CloneJET PCR cloning kit (Fermentas, Lithuania) and ligated plasmids were transformed to JM109 Z-competent cells. Plasmids were extracted with the Gene JET Plasmid Miniprep Kit (Thermo Scientific) and sequencing was done with an ABI PRISM 310 Genetic Analyzer (Life Technologies, USA).

\section{Results}

\subsection{Gel electrophoresis and sequence analysis of RT-PCR amplified fragments}

Electrophoretic patterns of RT-PCR amplified fragments (Fig. 1) of the analyzed genes revealed that these are at the expected size. The amplified fragments were sequenced (Supplementary file 1) and pairwise alignment with the sequence data in the Potato-TD revealed that the analyzed fragments are identical with the appropriate transcripts.

\subsection{Expression analysis of protease inhibitor genes}

The aspartic-, the cysteine and the serine protease inhibitors showed significant up-regulation (Fig. 2), while the analyzed 

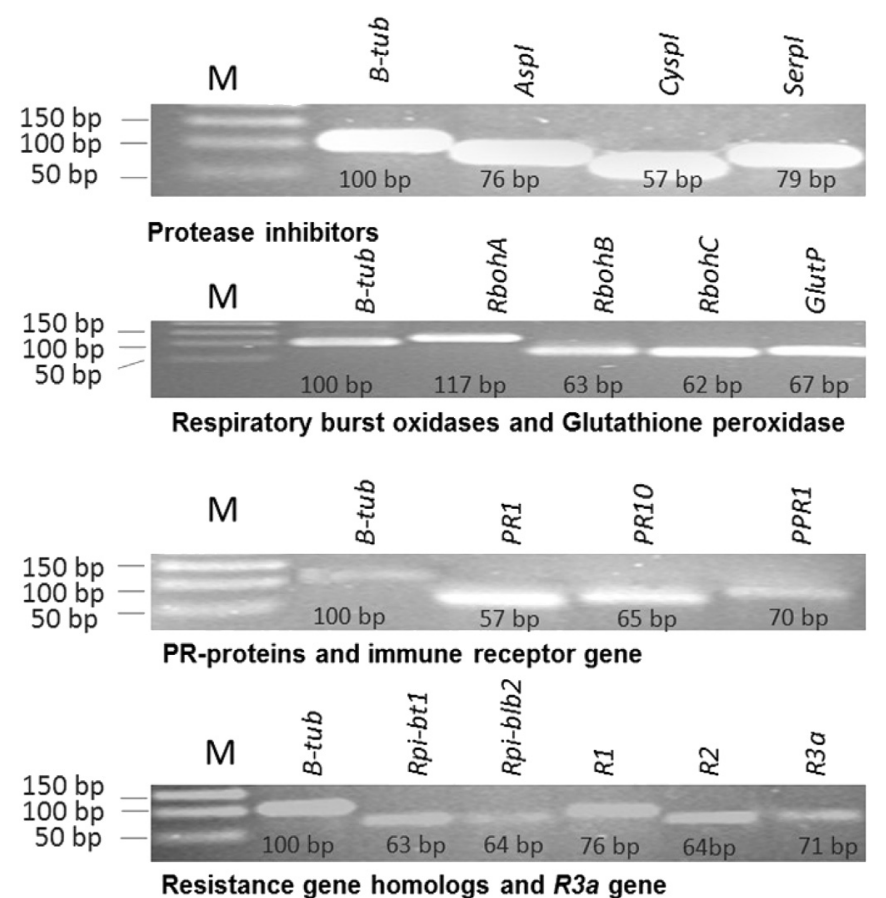

Fig. 1. Electrophoretogram of the genes analyzed by qPCR. M: molecular size marker (50 bp); B-tub: $\beta$-tubulin gene (housekeeping gene); Protease inhibitors: aspartic protease inhibitor (AspI), cysteine protease inhibitor (CyspI) and serine protease inhibitor (SerpI); Respiratory burst oxidase homologs and Glutathion peroxidase genes: RbohA, $B, C$, glutathione peroxidase (GlutpI); PR proteins and immune receptor gene: PR1, PR10 and PPR1; Resistance gene homologs: Rpi-bt1 homolog, Rpi-blb2 homolog, $R 1, R 2$ homologs and $R 3 a$ gene.

Kunitz-type protease inhibitor showed no expressional change. The aspartic protease inhibitor showed up-regulation in two time points, with values significantly differing from each other and from the other time points. First and strongest peak was registered at the
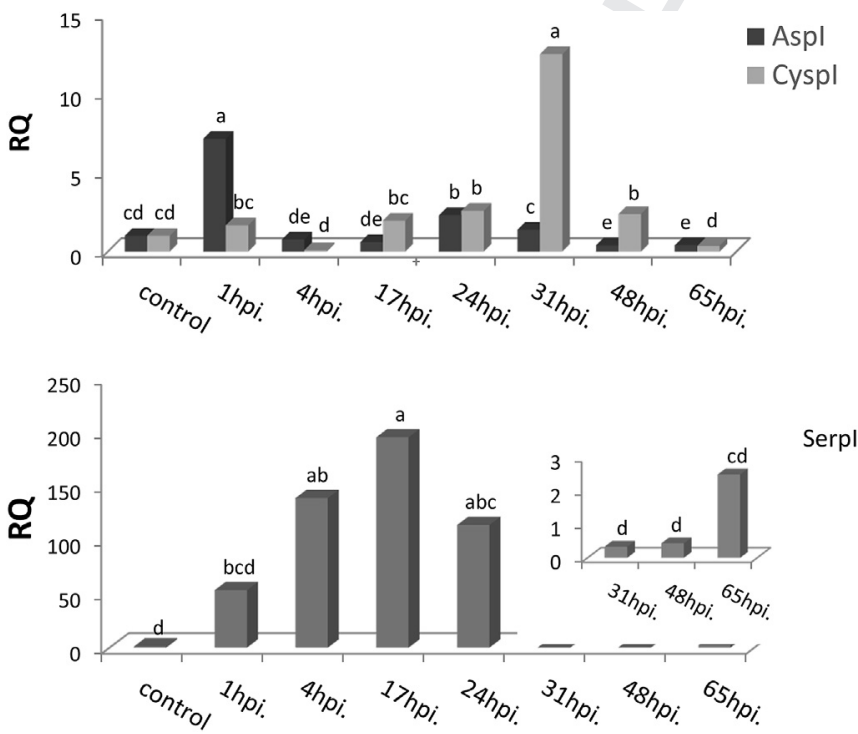

Fig. 2. Expression profile and RQ (relative quantitation) mean comparison of aspartic and cysteine protease inhibitors (AspI and CypI) (2.1.) and of the serine protease inhibitor (SerpI) (2.2.). Expression value for each gene in each time point (hpi: hours post inoculation) represents the mean of three biological replicates. The RQ value indicates the copy number fold change of the treated to mock inoculated samples. The same letters indicate that there is no significant difference of those values at $\mathrm{P}<0.01$ level. 1st hour after inoculation with a 7.1 fold increase, while the second was a less strong peak with a 2.3 fold increase at the $24 \mathrm{hpi}$. Between these and at the later time point expression of the AspI gene showed decreasing. The cysteine protease inhibitor showed a slight, 1.6 fold up-regulation at $1 \mathrm{hpi}$, and almost no expressional increase at 4 hpi. Then it slightly increased again and got its expressional maximum with a 12.5 fold increase at $31 \mathrm{hpi}$. In later sampling time points its expression rapidly decreased (Fig. 3).

The serine protease inhibitor showed an immediate strong upregulation after the inoculation with the peak of expression found at 17 hpi showing a 195.4 fold increase. Then it rapidly decreased, and at $31 \mathrm{hpi}$ and later almost no up-regulation was observed (Fig. 2.2).

\subsection{Expression analysis of reactive oxygen species}

All respiratory burst oxidase homologs showed significant upregulation at $4 \mathrm{hpi}$. RbohA and $R b o h C$ showed a 10.3 and 7.8 copy number increase at this time point, respectively (Fig. 3.1), for $R b o h B$ this value was 211.8 (Fig. 3.2). RbohB showed strong, inoculation induced up-regulation with an 81.9 fold copy number increase at 1 hpi, while for the other two Rboh genes there was almost no expression change at $1 \mathrm{hpi}$. At later time points expression of all these three genes was almost identical with that of the control.

Interestingly, except a very slight, 1,6 fold copy number increase at $4 \mathrm{hpi}$, no significant expression change was observed for the glutathione peroxidase homolog in this $65 \mathrm{~h}$ period of analysis.

\subsection{Expression analysis of pathogenesis related protein genes and immune receptor gene}

Both pathogenesis related proteins in this study have different activation ranges. PR1 was immediately up-regulated by the inoculation, and its expression maximum was at 4 hpi where a 24.3 fold copy number was measured. Then its expression decreased rapidly almost to the level of the control. PR10 was up-regulated at $31 \mathrm{hpi}$ with an 18.7 fold copy number increase, then expression of this
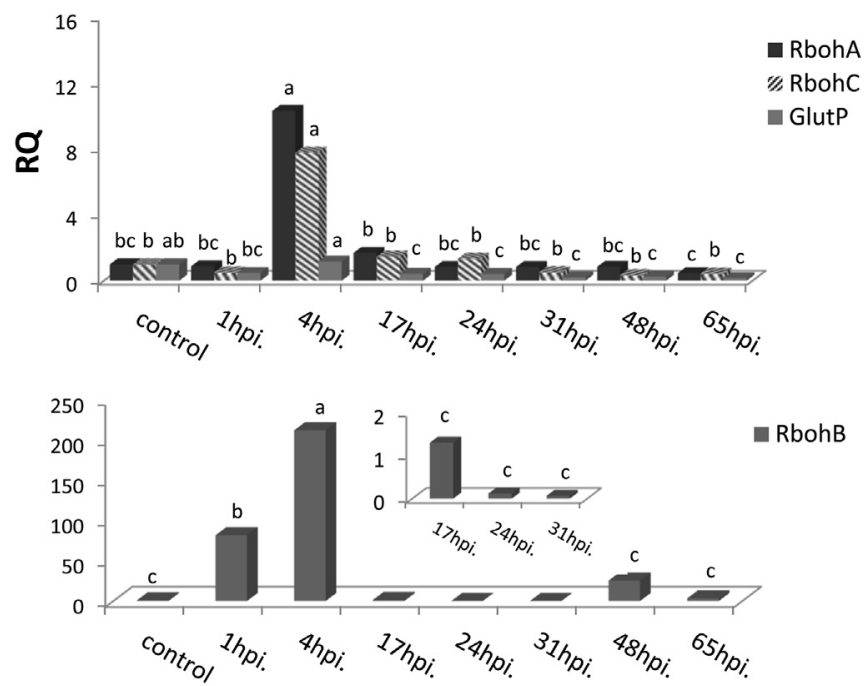

Fig. 3. Expression profile and $\mathrm{RQ}$ (relative quantitation) mean comparison of gene homologs of the RbohA and RbohC respiratory burst oxidases, and of glutathione peroxidase (GlutP) (3.1.), as well as of the respiratory burst oxidase RbohB (3.2). Expression value for each gene in each time point (hpi: hours post inoculation) represents the mean of three biological replicates. The RQ value indicates the copy number fold change of the treated to mock inoculated samples. The same letters indicate that there is no significant difference of those values at $\mathrm{P}<0.01$ level. 
gene decreased gradually. (Fig. 4) (Fig. 5).

PPR1, the plant immune receptor homolog, showed a 10.6 fold copy number increase at $4 \mathrm{hpi}$, and then the expression level of it was similar to the control (Fig. 4).

\subsection{Expression analysis of $N B-L R R$ genes}

Assembled contigs of the potato cultivar White Lady were annotated using the Solanum tuberosum L. group Phureja clone DM13-516-R44 reference genome. Beside many gene homologs, 82 NBLRRs which are related with resistance to $P$. infestans according to Jupe et al. (2012) [30] were detected in White Lady. These NB-LRR genes show homology with late blight resistance genes deriving from different wild Solanum species like $S$. demissum $(R 1, R 2$ homologs and R3a), Solanum bulbocastanum (Rpi-bt1 and Rpi-blb2) or Solanum venturii (Rpi-vnt1). The expression of four NB-LRR homologs, R1, R2, Rpi-bt1, and Rpi-blb2 and of the $R 3 a$ gene was examined in this study. The $R 1$ and $R 2$ homologs, as well as the $R 3 a$ gene showed constitutive expression during the examined time period, except that at 65 hpi for the $R 1$ homolog a 16.2 and for the $R 2$ homolog a very strong 174.4 fold copy number increase was measured. Interestingly, for the $R 3 a$ gene no expression change could be found in any of the analyzed time points (Fig. 5.1).

Among the Rpi gene homologs which show sequence similarity with $S$. bulbocastanum derived Rpi genes the Rpi-bt1 homolog was immediately up-regulated by the infection and got its expression maximum with 22.7 time change at $4 \mathrm{hpi}$, and then its expression decreased rapidly. The other analyzed Rpi gene homolog; the Rpiblb2 homolog showed a very slight up-regulation only in the first three fold points of the analysis (Fig. 5.2).

\section{Discussion}

Pathogens at the biotrophic phase require living host plant cells for their survival and development while they suppressing defense responses $[23,26]$. It is strongly believed that the earlier expression of defense genes has a great impact on resistance to the pathogen, and is in relation to systemic acquired resistance (SAR) characterized by coordinated activation of a specific set of genes in both local and distal tissues [29].

In our study ten of the 16 analyzed genes, the AspI, CyspI, SerpI, RbohA, RbohB, RbohC, PR1, PR10, PPR1 and Rpi-bt1 homolog had their expression maximum in the biotrophic phase after $P$. infestans inoculation. The aspartic protease inhibitor had its maximal

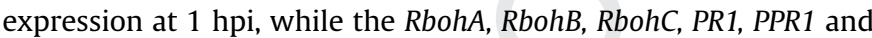
Rpi-bt1 homolog had their highest copy number fold change at 4 hpi. The serine protease inhibitor showed expression maximum at $17 \mathrm{hpi}$, and the CyspI and PR10 at $31 \mathrm{hpi}$. It is suggested that all these genes are involved in the suppression of the pathogen. It is known

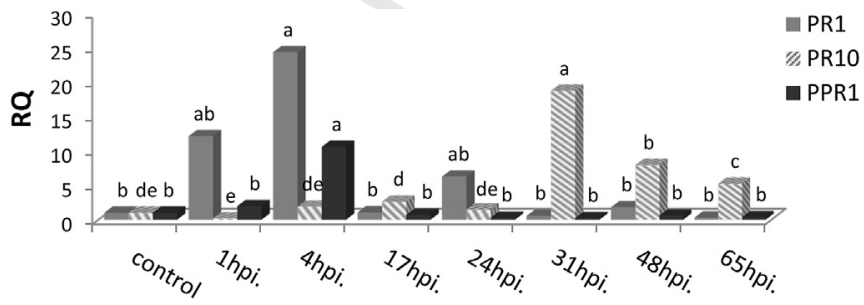

Fig. 4. Expression profile and RQ (relative quantitation) mean comparison* of pathogenesis related proteins (PR1 and PR10) and of the immune receptor gene (PPR1). Expression value for each gene in each time point (hpi: hours post inoculation) represents the mean of three biological replicates. The RQ value indicates the copy number fold change of the treated to mock inoculated samples. The same letters indicate that there is no significant difference of those values at $\mathrm{P}<0.01$ level.
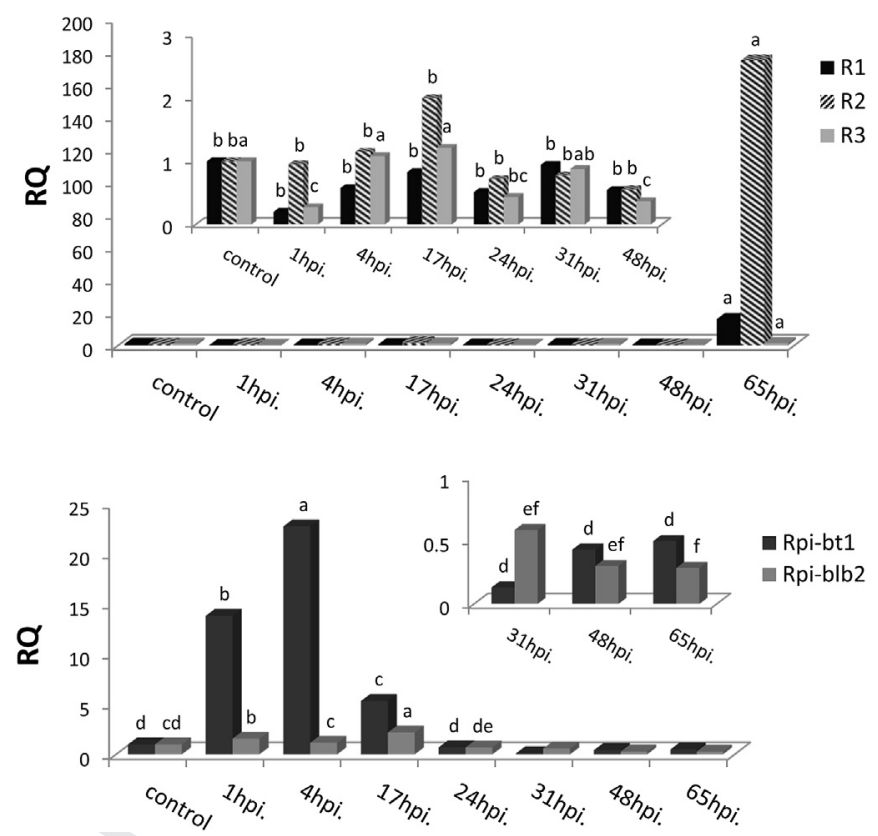

Fig. 5. Expression profile and RQ (relative quantitation) mean comparison of the $R 1$ and $R 2$ gene homologs and of the R3a gene (5.1.), as well as of the Rpi-bt1 and Rpi-blb2 gene homologs (5.2.). Expression value for each gene in each time point (hpi: hours post inoculation) represents the mean of three biological replicates. The RQ value indicates the copy number fold change of the treated to mock inoculated samples. The same letters indicate that there is no significant difference of those values at $\mathrm{P}<0.01$ level.

that these groups of genes encode antimicrobial products, inhibitor proteins and control host cell death at the site of infection.

The $R 1$ homolog and the $R 2$ homolog were also up-regulated, but only at 65 hpi. Avrora et al. (2008) [27] found, that in a compatible interaction $P$. infestans infected potato tissues turn necrotic at the 36-48 $\mathrm{h}$ period after inoculation. In our analysis both the CyspI and PR10 genes showed a decreasing up-regulation at 48 and $65 \mathrm{hpi}$, but their expression maximum was at $31 \mathrm{hpi}$. What is the role of these genes in this period of defense in an incompatible interaction, and whether these genes are also expressed in the necrotrophic phase in a compatible interaction needs further investigations.

The Kunitz-type inhibitor does not showed any expressional change, and almost no change was observed for the glutathione peroxidase and for the $R 3 a$ gene, as well as for the Rpi-blb2 homolog.

\subsection{Expression pattern of non-specific resistance genes to P. infestans}

\subsubsection{Protease inhibitors}

During the infection process, Phytophthora produces enzymes that target host cells. In return, plants encode secreted proteins that have proteolytic activities such as papain-like cysteine proteases [32] or function as protease inhibitors to suppress enzymatic activity of the pathogen [33]. However, members of the former group, like RCR3 homologs, PIP1 homologs or C14 homologs, could not be found among the annotated transcripts of the Potato-TD. Twenty gene homologs of different protease inhibitors were identified in the Potato-TD and four transcripts were up-regulated after Phytophthora infection. Fernandez et al. (2012) [19] performed a densitometric analysis of SDS-PAGE bands of apoplastic hydrophobic proteins that were extracted from tubers of resistant and susceptible potato cultivars $24 \mathrm{~h}$ after inoculation with $P$. infestans. 
The results showed that, except the Kunitz-type protease inhibitor, higher amounts of aspartic-, serine- and cysteine protease inhibitors were measured in the inoculated resistant samples compared to the mock inoculated control and to susceptible tubers. These results are very similar to the relevant findings of the present study, and indicate that Kunitz-type protease inhibitors may not act in the defense response during the early period of an incompatible potato - P. infestans interaction.

Other abundant protease inhibitors which have been linked to plant defense response against $P$. infestans are the trypsin and chymotrypsin inhibitors. Kim et al. (2005) found that increased levels of these compounds correlated with the resistance of the plants to the pathogen [34]. These belong to the serine protease inhibitor type that inhibits enzyme activity of the pathogen. Different types of these molecules including BTI-1, BTI-2, PT-1 have been found to play a role in resistance response in potato [35-37]. In our study the serine protease inhibitor was one of the most strongly up-regulated genes with an almost 200 fold copy number increase, indicate its role in the resistance response.

\subsubsection{Respiratory burst oxidases and glutathione peroxidase}

Respiratory burst oxidase homologs ( $R b o h$ ) are assigned as the main sources of reactive oxygen species and play a critical role in the signal transduction pathway and programmed cell death in the physiological process during hypersensitive reaction [38,39]. We found the highest level of expression for all examined $R b o h$ genes at the 4th hour post inoculation. ROS signaling in the plant cell has a dynamic and rapid nature. This event is a consequence of contrasting processes between ROS production and scavenging. To reach the pinnacle of balance between scavenging and production rate, rapid alteration of ROS levels occur in plant cells [39]. Therefore it is possible that in a resistant potato plant like White Lady upon the pathogen attack, a leap in value of ROS followed by activation of NADPH oxidase $R b o h$ genes are triggered by different stimuli.

The expressional changes of Rboh homologs showed the highest fold change for RbohB compared to other homologs in the test. A calcium-dependent protein kinase of potato, the StCDPK5 gene was found to activate the Strboh (S. tuberosum Rboh) A, B, C and D genes. The relative chemiluminescence intensity of these Strboh homologs showed the highest intensity for StrbohB gene [40]. In our qPCR analysis similar results have been obtained, i.e. that among the $R b o h$ genes the RbohB gene showed the highest up-regulation in resistance response to $P$. infestans.

Glutathion peroxidases reduce the level of hydrogen peroxide, that is produced during oxidative stress. The analyzed glutathion peroxidase of this study showed only a very slight up-regulation. This implies that this glutathione peroxidase homolog may not be included or may not have a significant role in the early period of the succesful defense response to $P$. infestans.

\subsubsection{PR-proteins and the immune receptor gene PPR1}

$P R 1$ protein is an antimicrobial compound which is expressed mostly at the early period of infection [41]. This protein has an inhibitory effect on zoospore germination and mycelial growth [42]. At the early stage of infection sporangia and germinating zoospores of $P$. infestans start to penetrate leaf tissues and cells, and to create haustoria. Increased production of PR1 in the biotrophic phase of infection may indicate its role for resistance against $P$. infestans. In cultivar White Lady around 10 and 23 relative quantitation value increase at 1 and $4 \mathrm{~h}$ after inoculation respectively, was observed, indicating that the pathogen was recognized and triggered the defense response.

While class 10 of pathogenesis related (PR10) proteins are well studied structurally, their biological function remains unclear [43].
Constabel et al. (1993) [43] found that the PR10a (previously known as STH-2) protein had no effect on $P$. infestans infection. In our study the analyzed $P R 10$ gene showed an 18.7 fold copy number increase at $31 \mathrm{hpi}$ and this level gradually decreased at 48 and 65 hpi. Therefore, it is considered that the analyzed transcript that showed homology with the PGSC0003DMG402001494 gene in our transcriptome analysis may be related to the resistance response to P. infestans infection.

Some plant resistance proteins have been identified which can make physical interaction with pathogen effectors. These interactions agree with the model of effector-triggered immunity following direct recognition of effectors like the ATR1 effector that is interacting with plant immune receptors PPR1 [44]. Sixteen homologs of plant immune receptors PPR 1 were identified in our Potato-TD, and interestingly 10 of them were up-regulated. The most up-regulated one was analyzed by qPCR in the present study. The expression of this PPR1 was verified in our qPCR analysis in which more than 10 fold copy number increase was registered at 4 hpi. This result indicates that this gene might be related to the resistance response of White Lady to $P$. infestans.

\section{2. $q P C R$ analysis of race-specific and broad spectrum resistance gene homologs}

In total, $82 \mathrm{NB}$-LRR containing homologs of race-specific $(R)$ and broad spectrum or race-nonspecific (Rpi) resistance genes were found in the Potato-TD and many of them were significantly upregulated after the inoculations. In the examined time period of the present quantitation analysis only the $R 1$ and $R 2$ homologs showed up-regulation, while for the $R 3 a$ gene no expressional change was observed. Up-regulation for the two $R$ gene homologs was found at the very last time point of the analysis, i.e. at $65 \mathrm{hpi}$. The $R 2$ homolog had the highest expression level among the analyzed resistance gene homologs. Our results of the $R 1$ homolog are in accordance with the results of Ros et al. [45], who found that changes in expression of the $R 1$ gene occurred only at the third day post inoculation. Our results on the $R 3 a$ gene are somewhat astonishing, since in the Potato-TD, a significant up-regulation was registered for this gene. Nevertheless, Huang et al. [21] found that the $R 3 a$ gene is a constitutively expressed gene which is in accordance with our qPCR results. The observed up-regulation in the transcriptome analysis for this gene may be due to small homologous reads from different genomic regions which may have amplified the signal of the $R 3 a$ gene.

QPCR of the Rpi-bt1 gene homolog showed a rapid and extended expression in the first half of the examined period, while no significant expressional change could be observed for the Rpi-blb2 gene homolog. The Rpi-bt1 and Rpi-blb2 genes were isolated from the diploid wild potato species $S$. bulbocastanum and are not present in the genetic background of White Lady. The presence of the homologs of these broad spectrum resistance genes in White Lady may indicate the common ancestral origin of $P$. infestans resistance genes in potato.

Quantitative analysis of resistance response genes identified by RNA-sequencing contributes to our understanding about their role in resistance. The qPCR analysis revealed up-regulation of 12 genes from the analyzed 16 genes, indicating their potential involvement in the resistance response to $P$. infestans. In this study, the nonspecific resistance gene homologs SerpI and $R b o h B$ and the $R 2$ resistance gene homolog had the highest expression level increase indicating that they may have a key role in incompatible defense response. Potato cultivar White Lady is a valuable source of different resistances and is used in our breeding programs. Selection of further biotic stress response genes from the Potato-TD and their expression analysis may facilitate the development of 
biomarkers even for non-specific resistance response genes, which then could be utilized in resistance breeding to $P$. infestans.

\section{Acknowledgments}

This work was supported by the OTKA 76485 and PD109063 02 funds of the Hungarian Academy of Sciences. István Cernák is supported by the János Bolyai Research Fellowship of the Hungarian Academy of Sciences.

\section{Appendix A. Supplementary data}

Supplementary data related to this article can be found at http:// dx.doi.org/10.1016/j.pmpp.2015.12.001.

\section{Uncited reference}

[31].

\section{References}

[1] W.E. Fry, S.B. Goodwin, Resurgence of the Irish potato famine fungus, Bioscience 47 (1997) 363-371.

[2] C. Gebhardt, J.P. Valkonen, Organization of genes controlling disease resistance in the potato genome, Ann. Rev. Phytopathol. 39 (2001) 79-102.

[3] J.K. Tiwari, S. Siddappa, B.P. Singh, S.K. Kaushik, S.K. Chakrabarti, et al., Molecular markers for late blight resistance breeding of potato: an update, Plant Breed. 132 (2013) 237-245.

[4] J. Rodewald, B. Trognitz, Solanum resistance genes against Phytophthora infestans and their corresponding avirulence genes, Mol. Plant Pathol. 14 (2013) $740-757$.

[5] J. Song, J.M. Bradeen, S.K. Naess, J.A. Raasch, S.M. Wielgus, G.T. Haberlach, et al., Gene RB cloned Solanum bulbocastanum confers broad Spectr. Resist. potato late blight PNAS 100 (2003) 9128-9133.

[6] V.G.A. Vleeshouwers, H. Rietman, P. Krenek, N. Champouret, C. Young, S.K. Oh, et al., Effector genomics accelerates discovery and functional profiling of potato disease resistance and Phytophthora infestans avirulence genes, PLOS ONE 3 (2008) e2875

[7] E.A.G. van der Vossen, J. Gros, A. Sikkema, M. Muskens, D. Wouters, P. Wolters, et al., The Rpi-blb2 gene from Solanum bulbocastanum is an Mi-1 gene homolog conferring broad-spectrum late blight resistance in potato, Plant J. 44 (2005) 208-222.

[8] A.A. Lokossou, T.H. Park, G. van Arkel, M. Arens, C. Ruyter-Spira, J. Morales, et al. Exploiting knowledge of $R /$ Avr genes to rapidly clone a new LZ-NBSLRR family of late blight resistance genes from potato linkage group IV, Mol. Plant-Microbe Interact. 22 (2009) 630-641.

[9] T.H. Park, J. Gros, A. Sikkema, V.G.A. Vleeshouwers, M. Muskens, S. Allefs, et al The late blight resistance locus Rpi-blb3 from Solanum bulbocastanum belongs to a major late blight $R$ gene cluster on chromosome 4 of potato, Mol. Plant-Microbe Interact. 18 (2005a) 722-729.

[10] T. Oosumi, D.R. Rockhold, M.M. Maccree, K.L. Deahl, K.F. McCue, W.R. Belknap Gene Rpi-bt1 from Solanum bulbocastanum confers resistance to late blight in transgenic potatoes, Am. J. Pot Res. 86 (2009) 456-465.

[11] N. Champouret, Functional Genomics of Phytophthora Infestans Effectors and Solanum Resistance Genes, PhD Thesis, Wageningen University, Wageningen, 2010

[12] W.E. Fry, S.B. Goodwin, Re-emergence of potato and tomato late blight in the United States, Plant Dis. 81 (1997) 1349-1357.

[13] M.G. Guevara, C. Almeida, J.R. Mendieta, et al., Molecular cloning of a potato leaf cDNA encoding an aspartic protease (St Asp) and its expression after P. infestans infection, Plant Phys. Biochem. 43 (9) (2005) 882-889.

[14] N. Doke, A strategy to enhance disease resistance of potato using the mechanism of the hypersensitive reaction against potato late blight, J. General Plant Path 71 (6) (2005) 444-447.

[15] H. Yoshioka, N. Numata, K. Nakajima, et al., Nicotiana benthamiana gp91 phox homologs NbrbohA and NbrbohB participate in $\mathrm{H}_{2} \mathrm{O}_{2}$ accumulation and resistance to Phytophthora infestans, Plant Cell 15 (3) (2003) 706-718

[16] V.G.A. Vleeshouwers, W. van Dooijeweert, F. Govers, S. Kamoun, L.T. Colon, Does basal $P R$ gene expression in Solanum species contribute to non-specific resistance to Phytophthora infestans, Phys. Mol. Plant Path 57 (1) (2000) $35-42$.

[17] M. Tian, E. Huitema, L. Da Cunha, T. Torto-Alalibo, S. Kamoun, A Kazal-like extracellular serine protease inhibitor from Phytophthora infestans targets the tomato pathogenesis-related protease P69B, J. Biol. Chem. 279 (25) (2004) 26370-26377.

[18] M.G. Guevara, C. Almeida, J.R. Mendieta, et al., Molecular cloning of a potato leaf cDNA encoding an aspartic protease (St Asp) and its expression after P. infestans infection, Plant Physiol. Biochem. 43 (9) (2005) 882-889.

[19] M.B. Fernández, M.R. Pagano, G.R. Daleo, M.G. Guevara, Hydrophobic proteins secreted into the apoplast may contribute to resistance against Phytophthora infestans in potato, Plant Physiol. Biochem. 60 (2012) 59-66.

[20] C.M. Pieterse, P.J. de Wit, F.P. Govers, Molecular aspects of the potato-Phytophthora infestans interaction, Neth. J. Plant Pathol. 98 (2) (1992) 85-92.

[21] S. Huang, E.A.G. van der Vossen, H. Kuang H, et al., Comparative genomics enabled the isolation of the R3a late blight resistance gene in potato, Plant J. 42 (2) (2005) 251-261.

[22] A.L. Bookout, D.J. Mangelsdorf, Quantitative real-time PCR protocol for analysis of nuclear receptor signaling pathways, Nucl. Recept Signal 1 (2003) e012.

[23] M.C. Heath, Hypersensitive response-related death, in: E. Lam, H. Fukuda, J. Greenberg (Eds.), Programmed Cell Death in Higher Plants, Springer, Germany, 2000, pp. 77-90.

[24] Y. Shibata, K. Kawakita, D. Takemoto, Age-related resistance of Nicotiana benthamiana against hemibiotrophic pathogen Phytophthora infestans requires both ethylene-and salicylic acid-mediated signaling pathways, MPMI 23 (9) (2010) 1130-1142.

[25] A.R. Hardham, L.M. Blackman, Molecular cytology of Phytophthora-plant interactions, Australas. Plant Pathol. 39 (1) (2010) 29-35.

[26] V.G.A. Vleeshouwers, W. van Dooijeweert, F. Govers, S. Kamoun, L.T. Colon, The hypersensitive response is associated with host and nonhost resistance to Phytophthora infestans, Planta 201 (6) (2000) 853-864.

[27] A.O. Avrova, P.C. Boevink, V. Young, L.J. Grenville-Briggs, P. van West, P.R.J. Birch, et al., A novel Phytophthora infestans haustorium-specific membrane protein is required for infection of potato, Cell Microbiol. 10 (2008) 2271-2284, http://dx.doi.org/10.1111/j.1462-5822.2008.01206.x.

[28] A. Mortazavi, B.A. Williams, K. McCue, L. Schaeffer, B. Wold, Mapping and quantifying mammalian transcriptomes by RNA-Seq, Nat. Meth 5 (7) (2008) $621-628$.

[29] C.T. Shepherd, A.N.M. Lauter, M.P. Scott, Determination of transgene copy number by real-time quantitative PCR, in: M.P. Scott (Ed.), Transgenic Maize: Methods and Protocols, Springer, Germany, 2009, pp. 129-134.

[30] F. Jupe, L. Pritchard, G.J. Etherington, K. MacKenzie, P.J.A. Cock, F. Wright, et al., Identification and localisation of the NB-LRR gene family within the potato genome, BMC Genomics 13 (75) (2012) 1-14.

[31] W. Durrant, X. Dong, Systemic acquired resistance, Annu. Rev. Phytopathol. 42 (2004) 185-209.

[32] K.H. Richau, F. Kaschani, M. Verdoes, et al., Subclassification and biochemical analysis of plant papain-like cysteine proteases displays subfamily-specific characteristics, Plant Physiol. 158 (2012) 1583-1599.

[33] T.A. Valueva, V.V. Mosolov, Role of Inhibitors of Proteolytic Enzymes in Plant Defense against Phytopathogenic Microorganisms (Moscow), Biochemistry 69 (11) (2004) 1305-1309.

[34] J.Y. Kim, S.C. Park, M.H. Kim, H.T. Lim, Y Park, K.S. Hahm, Antimicrobial activity studies on a trypsin-chymotrypsin protease inhibitor obtained from potato, Biochem. Biophys. Res. Comm. 330 (3) (2005) 921-927.

[35] J.Y. Kim, S.C. Park, I. Hwang, et al., Protease inhibitors from plants with antimicrobial activity, Int. J. Mol. Sci. 10 (6) (2009) 2860-2872.

[36] J.J. Ruan, H. Chen, J.R. Shao, Q. Wu, X.Y. Han, An antifungal peptide from Fagopyrum tataricum seeds, Peptides 32 (6) (2011) 1151-1158.

[37] L.A. Mur, L.I. Laarhoven, F.J. Harren, M.A. Hall, A.R. Smith, Nitric oxide interacts with salicylate to regulate biphasic ethylene production during the hypersensitive response, Plant Physiol. 148 (3) (2008) 1537-1546.

[38] I. Thoma, C. Loeffler, A.K. Sinha, et al., Cyclopentenone isoprostanes induced by reactive oxygen species trigger defense gene activation and phytoalexin accumulation in plants, Plant J. 34 (3) (2003) 363-375.

[39] R. Mittler, S. Vanderauwera, N. Suzuki, et al., ROS signaling: the new wave? Trends Plant Sci 16 (6) (2011) 300-309.

[40] M. Kobayashi, M. Yoshioka, S. Asai, et al., StCDPK5 confers resistance to late blight pathogen but increases susceptibility to early blight pathogen in potato via reactive oxygen species burst, New Phytol. 196 (1) (2012) 223-237.

[41] E. Orłowska, A. Basile, I. Kandzia, B. Llorente, H.G. Kirk, C. Cvitanich, Revealing the importance of meristems and roots for the development of hypersensitive responses and full foliar resistance to Phytophthora infestans in the resistant potato cultivar, Sarpo Mira J. Exp. Bot. 63 (13) (2012) 4765-4779.

[42] T. Niderman, I. Genetet, T. Bruyere, et al., Pathogenesis-related PR-1 proteins are antifungal (isolation and characterization of three 14-kilodalton proteins of tomato and of a basic PR-1 of tobacco with inhibitory activity against Phytophthora infestans), Plant Physiol. 108 (1) (1995) 17-27

[43] C.P. Constabel, C. Bertrand, N. Brisson, Transgenic potato plants overexpressing the pathogenesis-related STH-2 gene show unaltered susceptibility to Phytophthora infestans and potato virus X, Plant Mol. Biol. 22 (5) (1993) 775-782.

[44] H. Fernandes, K. Michalska, M. Sikorski, M. Jaskolski, Structural and functional aspects of PR-10 proteins, FEBS J. 280 (2013) 1169-1199, http://dx.doi.org/ 10.1111/febs.12114.

[45] B. Ros, F. Thümmler, G. Wenzel, Analysis of differentially expressed genes in a susceptible and moderately resistant potato cultivar upon Phytophthora infestans infection, Mol. Plant Pathol. 5 (3) (2004) 191-201. 